The Ambivalence of Two-part Tariffs

for Bottleneck Access

Steffen Hoernig Ingo Vogelsang

Working Paper n. 568

October 2012

This working paper's content details the views of its author(s), which are not necessarily those of the "Faculdade de Economia." 


\title{
The Ambivalence of Two-Part Tariffs for Bottleneck Access
}

\author{
By Steffen Hoernig and Ingo Vogelsang
}

This version: October 11, 2012

\begin{abstract}
Two-part tariffs, when used at the retail level, increase efficiency by lowering the price of marginal units. The same potential for higher efficiency exists for two-part tariffs at wholesale level for a given market structure, but the fixed part of the wholesale tariff can negatively affect the latter. In a simulated competition model of next-generation telecommunications access networks that has been calibrated with engineering cost data, we show that the latter effects strongly outweigh the former. That is, substituting a cost-based linear wholesale access tariff with revenue-equivalent two-part tariffs reduces the number of access seekers and therefore leads to higher prices and lower welfare and consumer surplus.
\end{abstract}

\section{Introduction}

Since the "marginal cost controversy" initiated by Coase (1946) two-part tariffs have played a prominent role in the literature on optimal price regulation. Coase had argued that marginal cost prices proposed by Hotelling (1938) and others would lead to deficits that would need to be covered by distortionary taxes, while two-part tariffs would allow cost coverage without further distortions. Later work showed that this first-best outcome only results in those cases where no customer is excluded by the fixed fee. However, two-part tariffs could still be welfare-superior to any linear tariffs (Willig, 1978) and could easily be implemented in practice.

This very positive view of two-part tariffs, however, does not necessarily extend to regulated input prices. The reason, first worked out by Ordover and Panzar (1980 and 1982), is that firms purchasing inputs compete with each other so that the two-part tariffs may influence and possibly distort this competition. Nevertheless, given that over time price regulation has become less and less an issue of final goods markets and more and more an issue of bottleneck inputs and given that many of these bottlenecks involve very high fixed costs and low marginal costs, linear input prices may be quite inefficient and two-part tariffs for inputs therefore appear to be desirable.

This problem exists, for example, for next generation telecommunications access networks in the form of fiber-to-the-home (FTTH) that are being built from scratch. In this case the network provider has to build out whole geographic areas independent of who subscribes to the network. This involves very high fixed (and sunk) costs, while the costs of connecting individual subscribers are quite low. We are here concentrating on the GPON technology. ${ }^{1}$ Wholesale access can in this case be

\footnotetext{
${ }^{1}$ The two currently most relevant architectures for FTTH are Ethernet Point-to-Point (P2P) and GPON. A P2P FTTH fiber architecture deploys individual fiber access lines from a Metropolitan Point of Presence (MPoP) to each customer home. In contrast, the GPON technology is designed for Point-to-Multipoint fiber plants. It concentrates the traffic of a significant number of customer access fibers at an intermediate optical splitter
} 
provided via bitstream access. Under linear access charges the access seekers would pay a monthly fee per subscriber, which is usually based on the long-run average incremental costs (LRIC) of access and which is much higher than the marginal cost of access. This can involve a substantial allocative distortion. If, in contrast, the fixed costs (or a large fraction of them) are distributed via the fixed fee of a two-part tariff the variable fee can approach marginal costs, potentially leading to lower prices for end users. This allocative efficiency effect is the great advantage of such a two-part tariff. On the other hand, the large fixed fee combined with the lower end-user prices may induce some competitors to exit the market. This would reduce competition, leading to an anti-competitive effect. In the current paper we will use numerical simulations in a realistic context of GPON FTTH access to show the interaction of these two effects.

The next section briefly reviews the literature on two-part wholesale access tariffs. Section 3 then describes the background of the numeric modeling approach. Section 4 provides and discusses the results. The paper ends with brief conclusions.

\section{Literature review}

Compared to the extensive literature on two-part tariffs in general and even to the literature on regulated two-part tariffs for end users, the literature on two-part tariffs for inputs appears to be very small. The above-mentioned article by Ordover and Panzar (1982) set the stage by establishing that "...for the empirically relevant class of production processes in which the purchased input is required in fixed proportion to output...a two-part tariff is never optimal from either a profit or welfare maximizing standpoint." They show this for the case of perfect downstream competition and with the monopolistic input supplier only operating upstream. In contrast, we will look at the case of imperfect downstream competition with a vertically integrated input supplier and with a further integrated supplier, who does not sell the essential input.

Panzar and Sibley (1989) come closer to our problem by analyzing an industry with an upstream monopoly and imperfect competition downstream and with a regulator who tries to influence downstream outcomes indirectly by regulating only the bottleneck input price but who has to leave the retail pricing to the input buyers. It turns out that, if the number of downstream firms is fixed and if the upstream and downstream firms earn positive profits the welfare optimal two-part access charge involves a variable access charge below marginal cost. This is because the two-part tariff can then correct for the imperfect competition result downstream. However, with free entry downstream the variable welfare-optimal access charge will be larger (smaller) than marginal cost of access if at the market equilibrium there exist locally decreasing (increasing) returns downstream. ${ }^{2}$ This latter result is somewhat artificial, though, since it is derived under the assumption that the number $n$ of firms is large enough so that (a) differentiation of welfare with respect to $n$ is feasible and (b) the free entry equilibrium involves zero profits for the downstream firms (contestability). Implicitly, these results reverse those of Ordover and Panzar (1982) because a linear tariff can be viewed as a special kind of two-part tariff with a fixed access charge $A=0$. Thus, the introduction of market imperfections downstream may change the previous negative results and may leave open if

location (Distribution Point) onto a single feeder fiber that then leads to the MPoP. The GPON technology is less costly than P2P but also provides substantially lower speed and less security/reliability.

${ }^{2}$ With free entry, the optimal variable access charge a will be equal to marginal costs if there are locally constant returns downstream. 
two-part tariffs for regulated inputs will improve regulation over linear access charges. In contrast to Panzar and Sibley (1989) we here deal with a limited number of downstream firms offering differentiated services. In this case free-entry equilibria can involve positive downstream profits (but no losses). ${ }^{3}$

Some other works analyze regulated two-part tariffs for inputs as regulatory tools for specific purposes. For example, Laffont and Tirole (1993) use the fixed part of a two-part tariff as a device for turning government subsidies used for providing incentives in a principal-agent framework into a self-financing device. Vogelsang (2001) uses two-part tariffs as incentive devices for electricity transmission regulation. In this case, the purchasing load-serving entities (LSE) downstream may not necessarily compete with each other. Another example is Brito et al. (2009), who use two-part tariffs on inputs to induce an incumbent to invest in new infrastructure. Inderst and Shaffer (2009) consider discriminatory two-part tariffs for inputs as a device for favoring more productive over less productive downstream firms.

A few works describe regulated two-part input tariffs in practice. Some initial non-linear pricing of telecommunications carrier access is described in Mitchell and Vogelsang (1991). Examples of other industries, such as gas, railroads and electricity are found in Biggar (2001). The latter author points out that non-linear input pricing is common in those industries but not so common in telecommunications. Nevertheless, we concentrate our numerical example on the latter.

\section{Modeling background}

In order to demonstrate the effects of regulated two-part tariff access charges on prices, competition, profits and welfare we draw upon the combination of a costing and competition model from Hoernig et al. (2010 and 2012). The basic structure of the model is given by Figure 1. The numeric cost model calculates cost functions (a) for an FTTH incumbent providing bitstream access to FTTH entrants and retail services to end users, (b) for an open number of symmetric FTTH entrants, and (c) for cable as an alternative vertically integrated network provider, who does not offer access to others. The cost model

Figure 1: Overview of modeling framework

\footnotetext{
${ }^{3}$ Valletti (1998) analyzes regulated non-linear access tariffs for two given downstream firms competing in a Cournot framework.
} 


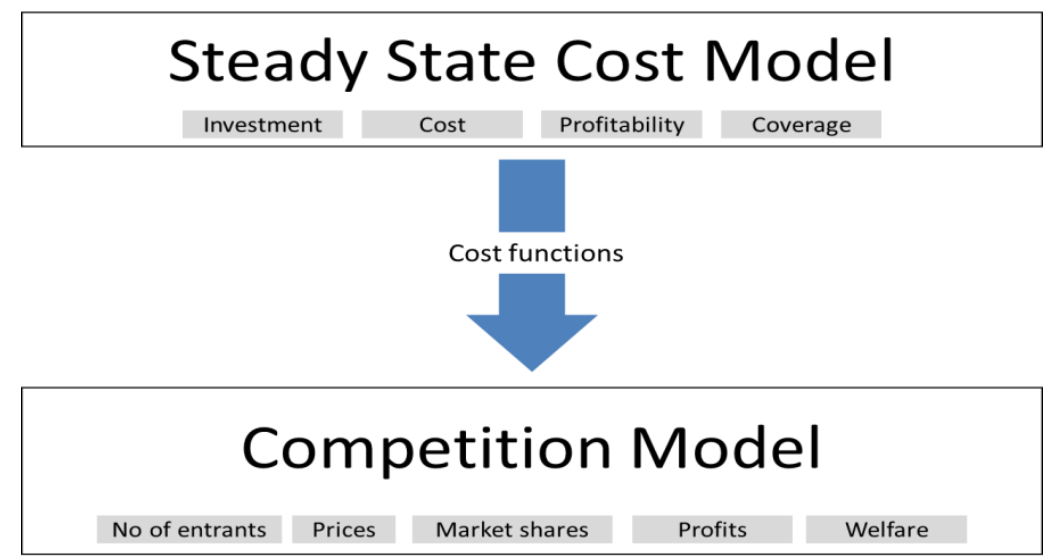

Source: Hoernig et al. (2010)

also calculates bitstream access charges, based on cost coverage for a predicted output quantity for FTTH access (which includes the incumbent). The cost functions then feed into a numeric competition model that allows for product differentiation among all competitors and that can be run with varying numbers of entrants in order to allow for a free entry and free exit feature. We here only provide the barest description of the models and ask the interested reader to consult Hoernig et al. (2010) or the shorter version in Hoernig et al. (2012) for more detailed information.

The cost model is built for a generic European country named "Euroland" that is divided into 8 areas called clusters ordered by declining network density. For purposes of the current modeling exercise we only include the densest four clusters in order to assure viability of a GPON FTTH network with bitstream-dependent entrants. Only the GPON access network is fully modeled, while the cable network's cost function for clusters 1-4 is assumed based on our assessment after discussions with industry experts. Assuming linear bitstream charges the cost functions are given in Table 1. The cost functions are split between the access and concentration network stage and the downstream stage

Table 1: Cost functions as inputs to the competition model

\begin{tabular}{|l|l|l|l|}
\hline & Fibre investor & Fibre bitstream entrant & Cable \\
\hline NetCo fixed cost per month & $94 \mathrm{M} €$ & $0 €$ & $20 \mathrm{M} €$ \\
\hline $\begin{array}{l}\text { NetCo var. cost per } \\
\text { subscriber }\end{array}$ & $6.52 €$ & $\begin{array}{l}22.05 € \\
\text { (bitstream charge) }\end{array}$ & $12.00 €$ \\
\hline $\begin{array}{l}\text { OpCo fixed cost per month } \\
\text { OpCo } \text { var. per }\end{array}$ & $2.7 \mathrm{M} €$ & $2.7 \mathrm{M} €$ & \\
\hline \begin{tabular}{l} 
Subscriber \\
\hline
\end{tabular} & $10.57 €$ & & \\
\hline
\end{tabular}


(including, in particular, the core networks and retail costs) as if the incumbent and entrants were (for accounting purposes) separated vertically into a "NetCo" and an "OpCo". ${ }^{4} \mathrm{~A}$ specific feature of telecommunications networks is that economies of scale not only persist in the access network but extend to the concentration and core networks. Thus, even if entrants buy bitstream access at linear prices they face economies of scale, which limit the viable number of firms.

Besides cost functions the competition model requires demand functions as crucial inputs. The numeric competition model used is based on the pyramid model (von Ungern-Sternberg, 1991), which is an extension of the Hotelling model to multiple firms. It therefore has a linear demand structure, where demand slopes are given by "transport costs" of equally-distributed customers to their preferred supplier and where the height is given by the valuation of customers located exactly at node locations. We determined the latter valuations (as willingness to pay $=$ WtP) from expert assessments of ARPUs ${ }^{5}$ for known services (single play, double play, triple play and business services) and assumptions about their composition and quality of service for the three types of players. We also gave the incumbent a goodwill advantage over entrants. The resulting WtP values assumed are shown in Table 2.

Table 2: Willingness-to-pay assumptions

\begin{tabular}{|l|l|l|}
$\begin{array}{l}\text { Incumbent } \\
\text { WtP }\end{array}$ & $\begin{array}{l}\text { Cable } \\
\text { WtP }\end{array}$ & Entrant WtP \\
\hline 90 & 82 & 83 \\
\hline
\end{tabular}

The transport cost parameters were determined from a priori considerations about closeness of substitution and by consistency requirements of the model (results should be consistent when access charges or the number of entrants change). The numeric competition model runs were only for the last stage of the competition game, where prices and quantities were determined for a given number of entrants and for given access charges. The previous stage determines the number of entrants and the stage before that determines the access charge. Thus, if in the last stage all entrants are profitable the model is run with a larger number of entrants. Conversely, if the (symmetric) entrants all make losses the model run is repeated with one less entrant. The model provides as outputs the prices charged by all firms, their market shares, their profits, consumer surplus and welfare.

For the purpose of testing the effects of two-part tariffs we had to determine an equivalence between linear and two-part tariffs as well as between various two-part tariff options. We did this by starting with the original linear tariff and assuming that any two-part tariff to be compared should at the same output - generate the same revenue as the linear tariff. Here we made a simplification that has some influence on the result but is quite realistic in describing what regulators actually do. It is that the regulated charge is based on a given expected quantity of output for which it just covers

\footnotetext{
${ }^{4}$ We here assume that bitstream access is provided at the core network node. It could also be provided at the MPoP.

${ }^{5}$ ARPUs are average revenues per user, which are commonly used as a measure of price levels achieved by firms, given the heterogeneity of their service offerings.
} 
the costs (LRIC) of the incumbent. This fixed projected quantity will in general differ from the equilibrium quantity resulting from the model. ${ }^{6}$

\section{Model results}

Table 3 gives the basic model result for the case of the linear bitstream charge of $a=22.05 €$ as calculated by the cost model. As can be seen the equilibrium number of firms is $N=6$, meaning there are 4 entrants besides the incumbent and the cable network. Due to higher WtP for the incumbent's services the end-user price for the incumbent is clearly higher than that of the entrants in spite of the incumbent's lower downstream cost. Cable has somewhat lower prices than both other types of firms, due to low marginal costs and low WtP. Nevertheless, cable profits are highest, due to low fixed costs along with low marginal costs and due to the large cable market share. The significantly lower profits of the incumbent are explained by the wholesale loss and by lower output that somewhat compensates the high downstream margin. The wholesale loss derives from the slightly higher than expected market share of cable, which was assumed to be $30 \%$ when calculating the bitstream access charge but turned out to be $31 \%{ }^{7}$ Profits of entrants are low to moderate, indicating that the equilibrium may be close to a situation with one less entrant. Welfare consists mostly of consumer surplus with about $7 \%$ derived from profits.

Table 3: Basic model results for linear bitstream charge

\begin{tabular}{|l|c|c|c|c|}
\hline Bitstream access charge & \multicolumn{2}{|l|}{$a=$ given $=22.05 €$} & & \\
\hline & General & Incumbent & Cable & Each Entrant \\
\hline Number of firms & 6 & & & \\
\hline End-user prices & & $40.31 €$ & $28.32 €$ & $37.67 €$ \\
\hline Profits & & $12.6 \mathrm{M} €$ & $23.9 \mathrm{M} €$ & $2.3 \mathrm{M} €$ \\
\hline Wholesale profits & & $-1.6 \mathrm{M} €$ & & \\
\hline Market shares & & 0.23 & 0.31 & 0.11 \\
\hline
\end{tabular}

\footnotetext{
${ }^{6}$ In Hoernig et al. (2010) the linear access charge is also endogenized as a special case. Such endogenized access charges may have superior welfare properties, as argued by Klumpp and Su (2010). However, Klumpp and Su compute "revenue-neutral" access charges, i.e. LRIC at equilibrium. They are different from "endogenous" access charges as defined by Fjell et al. (2010) and used in Nitsche and Wiethaus (2010). The latter two papers assume that access charges change with quantities out of equilibrium, and firms take their influence on access charges into account (Boffa and Panzar, 2012, use the same idea). Therefore "endogenous" access charges have better welfare properties than "revenue-neutral" ones. They are, however, difficult to calculate in practice. We briefly discuss below how our results for two-part tariffs change under endogenized access charges.

${ }^{7}$ Note that as in the Hotelling model the total number of subscribers to all the firms is fixed. For the first four clusters it is $8.64 \mathrm{M}$. As a result, only the distribution of customers between firms is affected by pricing.
} 


\begin{tabular}{|l|c|l|l|l|}
\hline Welfare & $446 \mathrm{M} €$ & & & \\
\hline Consumer surplus & $413 \mathrm{M} €$ & & & \\
\hline
\end{tabular}

In the following we consider the effects of using two-part wholesale access tariffs instead of linear access charges.

Two-part access tariffs are calculated on the basis of long-run average incremental costs (LRIC) for the projected outputs. Defining $K_{0}$ as the total fixed cost of FTTH access, $c_{0}$ as average variable cost of access, $Q_{0}$ as the total expected access quantity purchased by entrants and self-provided to the incumbent's downstream OpCo, and $\mathrm{n}$ as the total number of firms using the FTTH access technology. Then total LRIC is the sum of variable and fixed costs of FTTH access, $K_{0}+c_{0} Q_{0}$, which has to equal access revenue under two-part tariffs, $A n+a Q_{0}$. Therefore, $A=(K+(c-a) Q) / n$. We can then vary the variable access charge ' $a$ ' and generate fixed fees ' $A$ ' in such a way that LRIC is achieved for the projected output. ${ }^{8}$

In Figure 2 the vertical axis gives both the fixed fee (red line) and the access quantity (the green and blue lines). The steep downward-sloping red line shows the relationship between the fixed fee and the variable fee for the regulated two-part tariff based on three entrants. The starting point on the right side is the linear tariff with a variable fee of $a=22.05 €$ and a fixed fee $A=0$. On the left side we can see that a reduction of the variable fee to about $6 €$ requires a fixed fee of about $24 \mathrm{M} €$, given that there are 4 wholesale users (incumbent plus three entrants). We have calculated two-part tariffs so that, at the assumed quantity of output, their revenue would cover LRIC. Since the actual access quantity decreases in the variable access charge, the revenue from a two-part tariff with a lower variable access charge will therefore exceed LRIC, as long as ' $a$ ' sufficiently exceeds the variable access costs. The two almost parallel horizontal lines give the projected and the actual access quantities (on the same scale as the monetary values on the left scale). The projected access quantity is the total quantity (8.64 $\mathrm{M}$ subscribers) times $70 \%$ or about $6.05 \mathrm{M}$ subscribers. However, because the initial market share of cable at $a=22.05 €$ is larger than expected the total access quantity is smaller than expected. Furthermore, because cable's market share declines as ' $a$ ' declines the actual access quantity increases slightly (for a given total number of firms) for a reduction in $a$.

\footnotetext{
${ }^{8}$ Here we assume that one fixed fee is paid for the whole area under consideration. Alternative assumptions could be made, e.g. one fixed fee per upstream access point, one fixed fee per city or region, etc. The market outcomes for these different cases should differ.
} 
Figure 2: Characterization of two-part access tariffs with three entrants

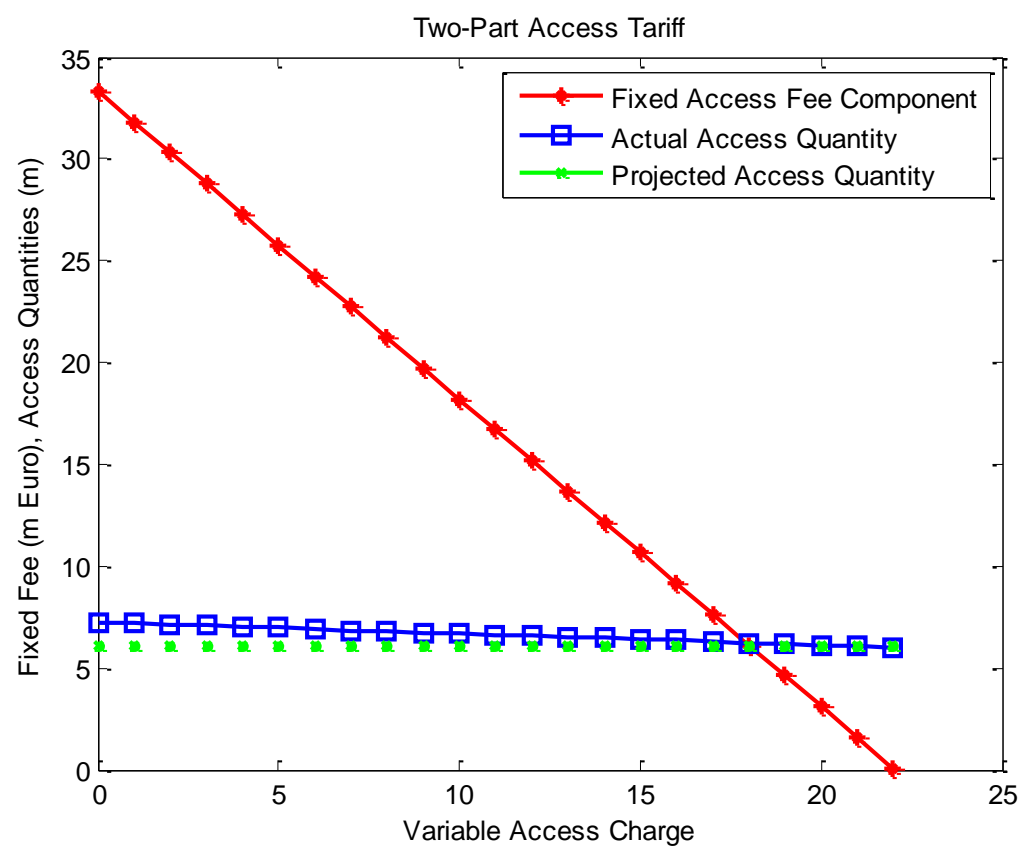

In the following we first continue to fix the number of entrants to $n=3$, which is one less than the free-entry equilibrium under linear access tariffs. We do this in order to show the benefits of twopart access tariffs without considering the potential anti-competitive effects.

Figure 3 shows that retail prices of all firms change monotonically with the reduction in variable access charges going along with an increase in fixed fees. Retail prices of entrants are a little more sensitive to the variable access charge than those of the incumbent and substantially more sensitive than those of cable. Overall, two-part tariffs have the asserted effects of bringing end-user prices closer to marginal costs. 
Figure 3: Effects of two-part wholesale access tariffs on retail prices with 3 entrants

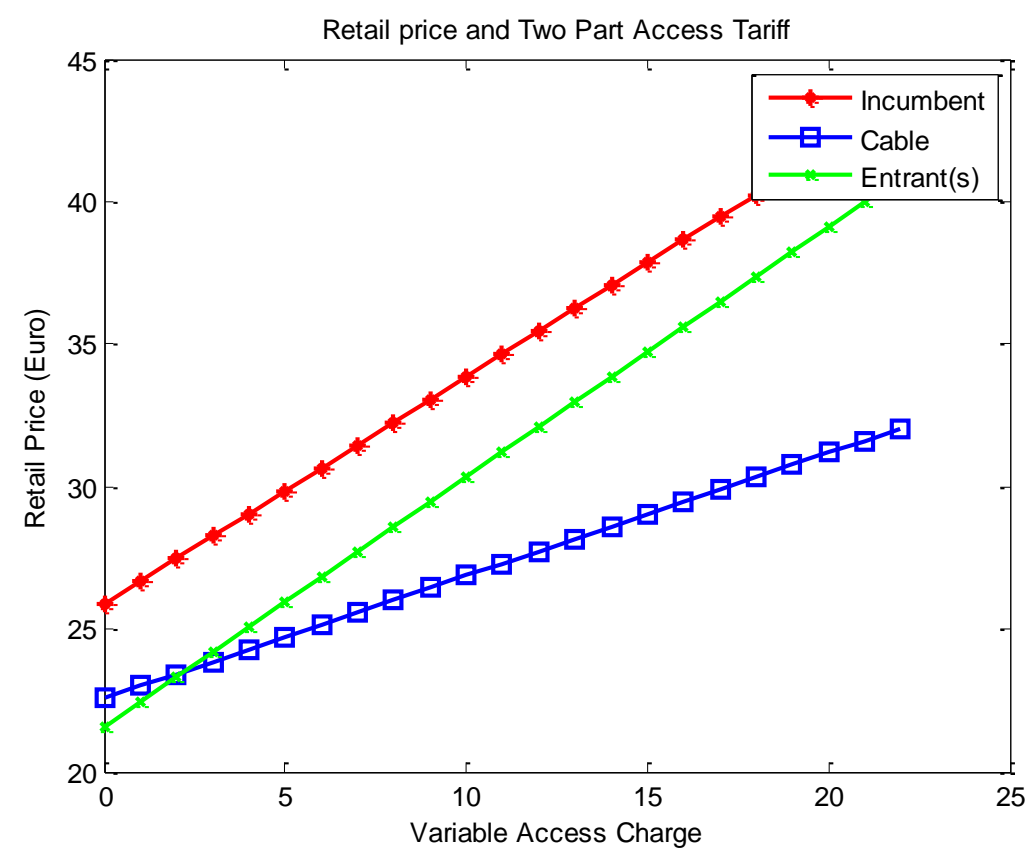

As Figure 4 demonstrates, in line with the price developments the entrants' market share increases at the expense of cable while that of the incumbent stays almost constant. ${ }^{9}$

Figure 4: Effects of two-part wholesale access tariffs on market shares with 3 entrants

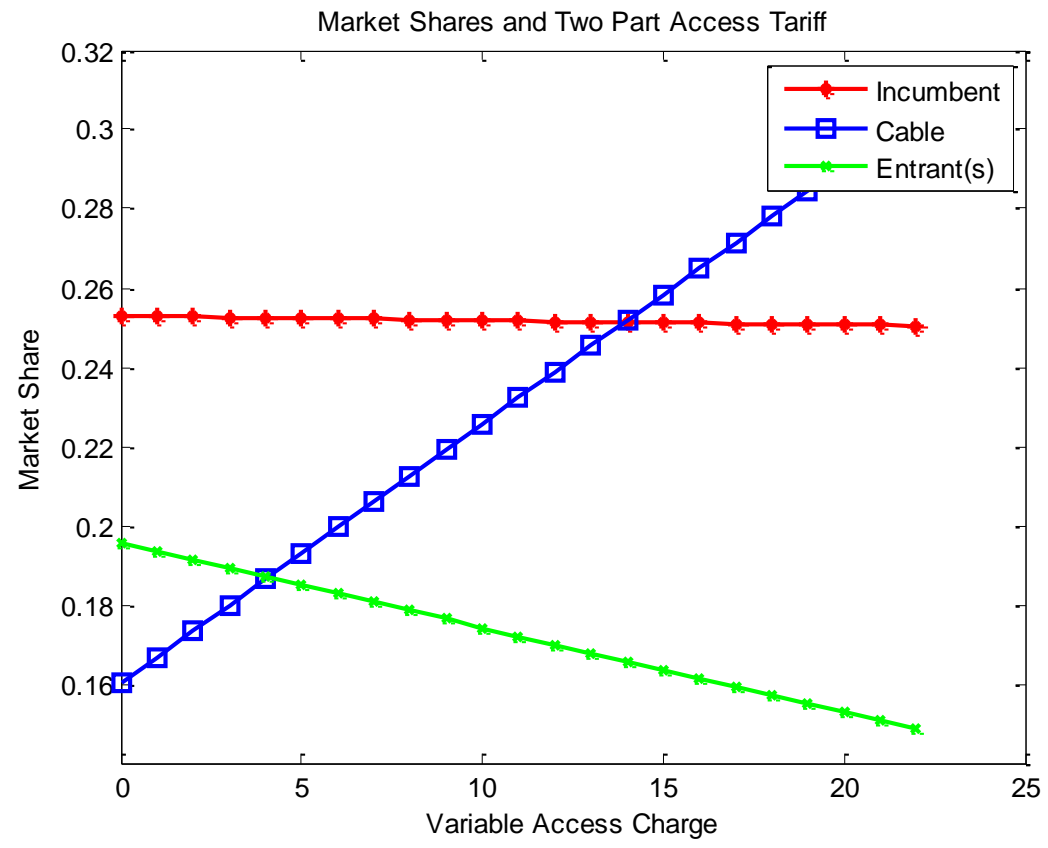

Figure 5 shows that all profits decline as the access charge is reduced. Furthermore, the entrants' profits become negative at a variable access charge of about $a=15 €$. Wholesale profits are non-

\footnotetext{
${ }^{9}$ Note that there are three entrants, each gaining about $5 \%$ market share.
} 
negative between about $a=6 €$ and $a=21 €$. The line for the incumbent's overall profits is concave because wholesale profit are concave and retail profits increase linearly in $a$.

Figure 5: Effects of two-part wholesale access tariffs on profits with 3 entrants

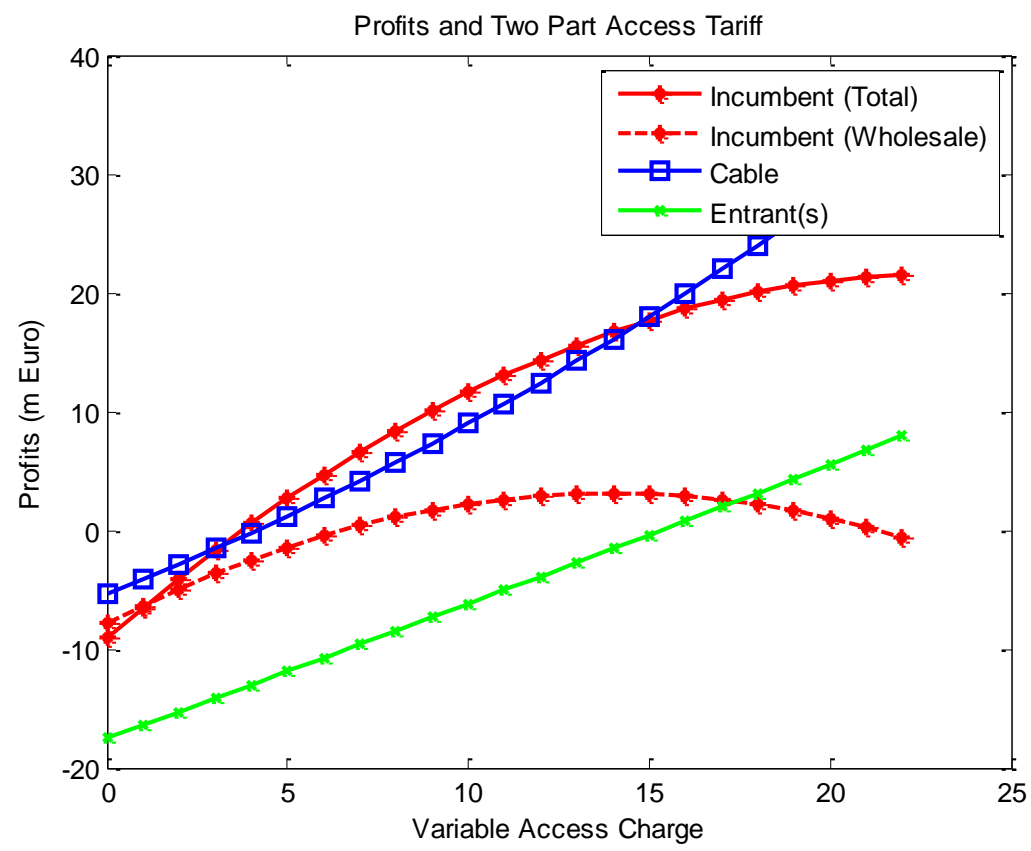

Two-part tariffs change the entrants' marginal costs that are relevant for pricing decisions. A similar reasoning holds for the incumbent because wholesale access charges are opportunity costs in the sense that selling at wholesale is the next best alternative to selling at retail. ${ }^{10}$ If the variable access fee is reduced, the resulting lower prices of incumbent and entrants lead the cable supplier to reduce its prices as well but not by enough to keep its market share. Entrants cannot benefit from the "scale economies" provided by two-part tariffs but rather only suffer from the increase in fixed costs. Summing up, for a given number of firms the economies of scale introduced by two-part wholesale access tariffs make competition fiercer, leading to lower profits of all firms.

Figure 6 gives the non-surprising result that consumer surplus strongly decreases as the tariff becomes more linear. However, total welfare is almost constant, because the consumer surplus increase due to lower end-user prices is compensated by lower profits.

\footnotetext{
${ }^{10}$ They are generally not the exact opportunity costs of the incumbent for access used internally as an input for its downstream services. For the exact opportunity costs see DeGraba (2003).
} 
Figure 6: Effects of two-part wholesale access tariffs on welfare and consumer surplus with 3 entrants

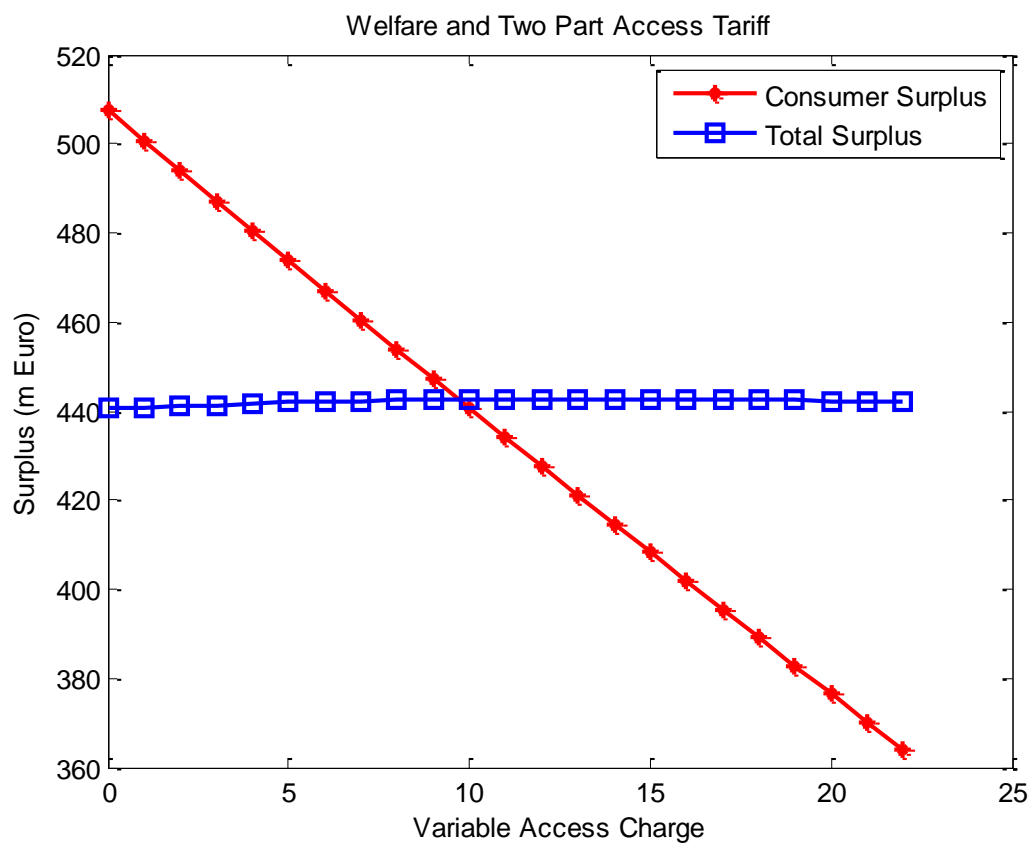

We now turn to the situation with free entry and exit, where an equilibrium is defined by positive profits for all firms and by negative profits for entrants if the number of entrants is increased by one. Figure 5 above already showed that the viability of three entrants is threatened very quickly when ' $a$ ' is reduced and ' $A$ ' increases accordingly. Thus, as ' $a$ ' is reduced more and more the number of firms in the market declines, leading to new equilibria with less competition. Figure 7 shows the drastic consequences of this case for the resulting end-user prices. Starting at $a=22.05 €$ the variable access charge is decreased and the fixed charge increased accordingly. The resulting reduction in retail prices leads to a reduction of entrants, starting from four down to one. Each time the number of entrants is reduced prices jump up for all firms. While, as in the previous analysis, the prices decline, as long as the number of entrants stays fixed, the overall trend of prices is upward, when variable access charges are reduced and fixed charges increased accordingly. 
Figure 7: Effects of two-part wholesale access tariffs on retail prices with free entry

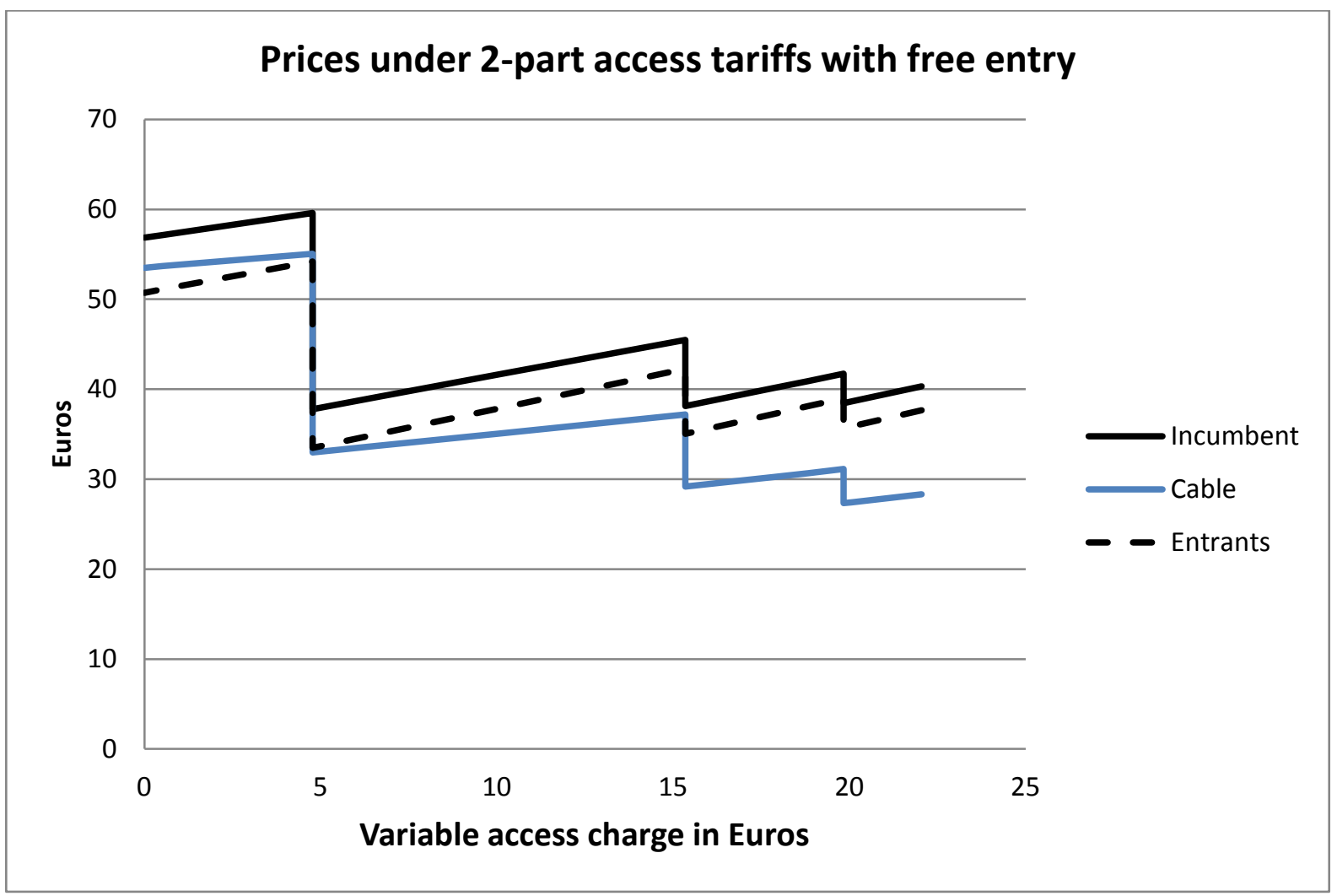

Figure 8 shows that market shares are influenced by an interaction of prices and the number of firms. Just as in Figure 4 market shares of cable decrease and of entrants increase when $a$ is reduced but the number of firms stays constant. However, a reduction in the number of entrants makes the incumbent's and cable's market share jump upward. While the same happens to the entrants' individual market shares, the sum of entrants' market shares is reduced by exit. Because in the range between $a=6 €$ and $a=21 €$ cable's market share is below the $30 \%$ assumed for setting the access charge at LRIC, the access charges are actually too high in this range and correct or slightly too low for $a<6 €$ and $a>21 €$. We have calculated endogenously determined access charge so that wholesale profit vanishes. This slightly increases the initial $a$ from $a=22.05 €$ to $a=22.38 €$. It otherwise only affects the distribution of profits between incumbent and entrants and the levels of $a$ at which entrants leave the market. These are changed by 0.10-0.60 €. 
Figure 8: Effects of two-part wholesale access tariffs on market shares with free entry

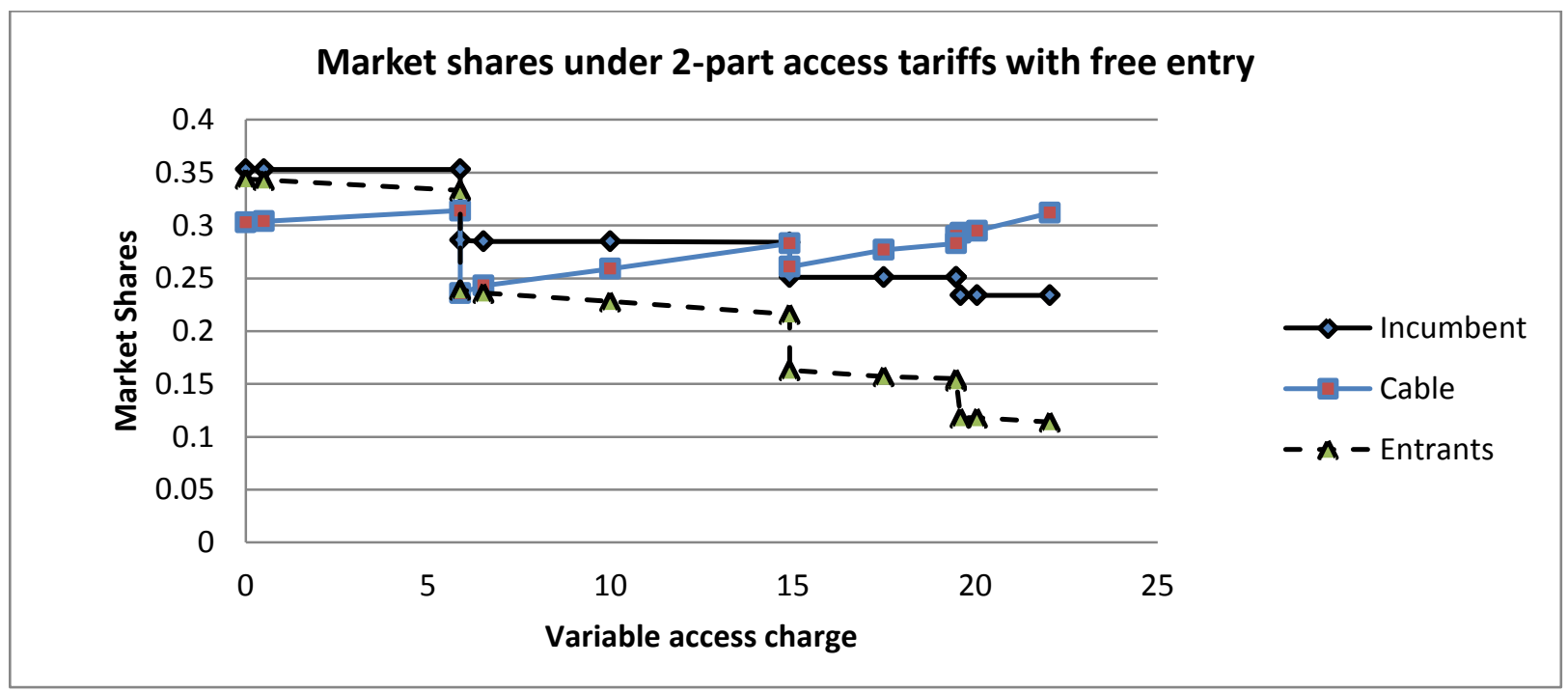

Similar effects as those on prices can be seen on profits in Figure 9. As the variable access charge is reduced and the fixed charge increased, profits decline, unless exit occurs, when they jump up. In general, cable is the greatest beneficiary of two-part tariffs. The incumbent suffers from reductions in wholesale profits. The remaining entrants strongly benefit from the reduction in the number of entrants.

Figure 9: Effects of two-part wholesale access tariffs on profits with free entry

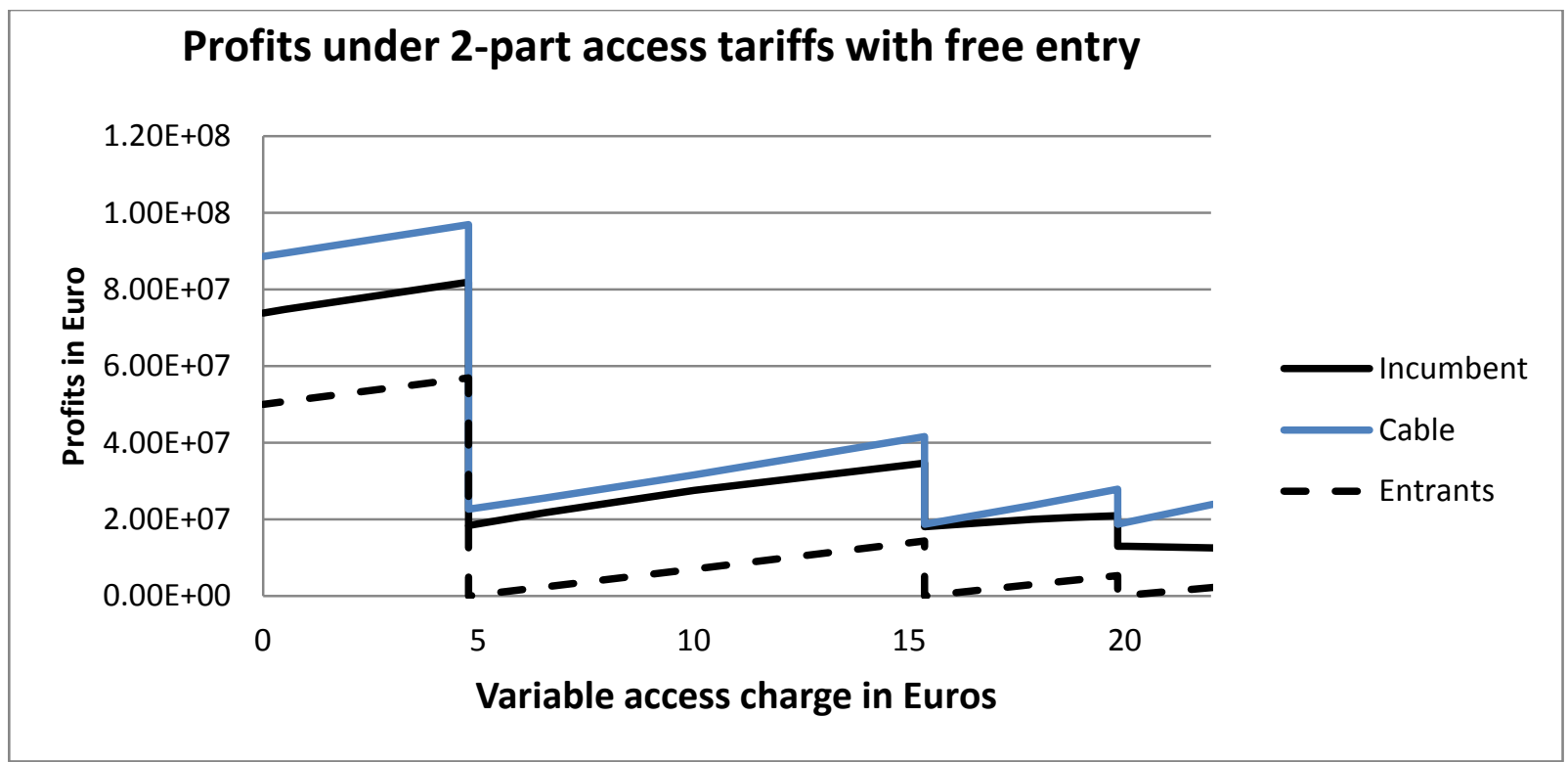

Figure 10 combines these results to give consumer surplus and welfare effects. Although, for a given number of firms, consumer surplus increases for reductions in variable access charges, the effect of exit of firms on average more than compensates for this benefit. Since exit of firms increases total profits substantially, this also increases the share of profits in total welfare. From the graphs it appears that in the simulated case welfare unambiguously suffers from the introduction of two-part access tariffs. This is not quite correct, because in some range welfare increases slightly if the variable access charge decreases as long as no firm exits. These increases in welfare are, however, 
too small to be visible in the graph. They are about $0.1-0.2 \%$ for every Euro reduction in a. In contrast, the exit of an entrant triggers a more visible reduction in welfare. This is surprising insofar as the exit reduces total fixed costs and has no effect on total output. Thus, the main effect here is that substitution occurs away from the more efficient technology (FTTH) towards the less efficient technology (cable).

Figure 10: Effects of two-part wholesale access tariffs on welfare and consumer surplus with free entry

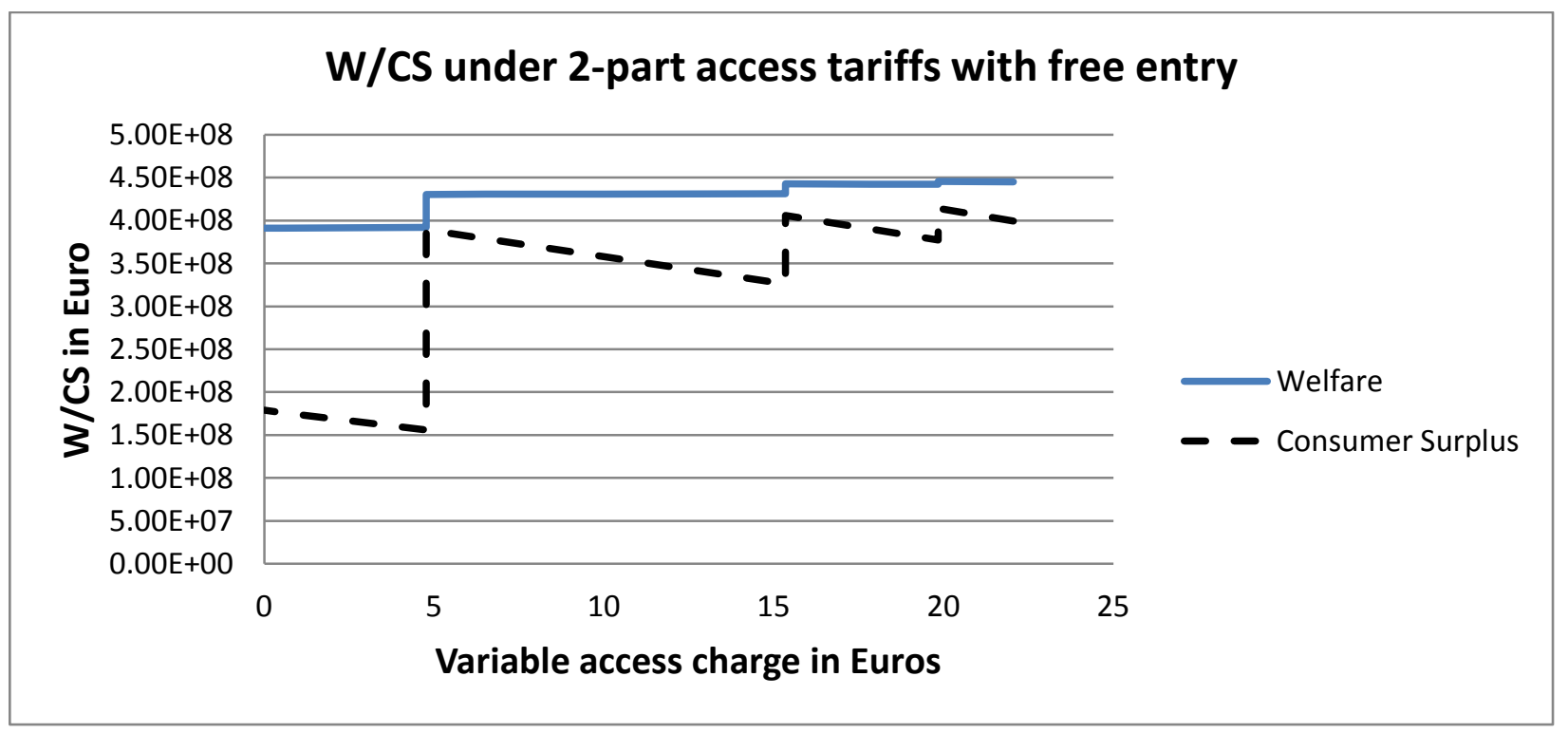

\section{Conclusions}

The main result of our numerical simulation has been that two-part wholesale access tariffs can lead to a reduction in the number of service competitors and can thereby have strongly anti-competitive effects, leading to sharply lower consumer surplus and mildly lower welfare. This result was certainly enhanced by the fact that in our model economies of scale existed even before the linear access charges were converted into genuine two-part access tariffs. In our model two-part access tariffs were beneficial to consumers and for welfare in general only in a small range between $a=22.05 €$ and $a=19.85 €{ }^{11}$ where no exit of entrants occurs. In this range the fixed fee $A$ remains quite low but, at $a=19.85 €$ it nevertheless reaches about $A \approx 2.7 \mathrm{M} €$. This, however, more than doubles the entrants' fixed costs downstream.

Since our model applies only to a specific industry further research should find out to what extent these results generalize to other network industries with similar bottleneck access problems. In the context of FTTH access one might also consider more localized fixed fees (at access points, or in specific regions) and calculate the effects on local market structure and how access charges could be tailored to local conditions.

\footnotetext{
${ }^{11}$ Note that with free entry and exit entrant 4 exits at 19.85 , but in figure 5 , where exit occurs at 15 , there are only three entrants present - see figure 9.
} 


\section{Bibliography}

Biggar, Darryl (2001). Access Prices and Competition, Prepared for the ACCC conference on Regulation and Investment, Sydney, March 26-27, 2001, retrieved from http://www.accc.gov.au/content/item.phtml?itemld=259604\&nodeld=487f9cfcccafec827b748d035 b4929e3\&fn=Darryl\%20Biggar\%20paper\%20-\%20Access\%20Pricing\%20\&\%20Competition.pdf .

Boffa, F. and J. Panzar (2012). Bottleneck co-ownership as a regulatory alternative, Journal of Regulatory Economics, 41(2), 201-215.

Brito, D., P. Pereira, J. Vareda (2010). Can two-part tariffs promote efficient investment on next generation networks? International Journal of Industrial Organization 28, 323-333.

Coase, R.A. (1946). The Marginal Cost Controversy, Economica 13, 169-182.

DeGraba, P. (2003). A Bottleneck Input Supplier's Opportunity Cost of Competing Downstream, Journal of Regulatory Economics23, 287-297.

Ergas, Henry, and Eric Ralph. 1997. Pricing Network Interconnection: Is the Baumol-Willig Rule the Answer? Paper prepared for the Trade Practices Commission, Australia.

Fjell, K., $\varnothing$. Foros and D. Pal (2010). Endogenous Average Cost Based Access Pricing, Review of Industrial Organization, 36(2), 149-162.

Hoernig, S., Jay, S., Neumann, K.-H., Peitz, M., Plückebaum, T., Vogelsang, I. (2010). Architectures and Competitive Models in Fibre Networks, Bad Honnef 2010, for download on www.wik.org and www.vodafone.com/eu.

Hoernig, S., Jay, S., Neumann, K.-H., Peitz, M., Plückebaum, T., Vogelsang, I. (2012). The impact of different fibre access network technologies on cost, competition and welfare", Telecommunications Policy, 36, 96-112.

Hotelling, H. (1938). The General Welfare in Relation to Problems of Taxation and of Railway and Utility Rates, Econometrica 6, 242-269.

Inderst, R., and G. Shaffer (2009). Market power, price discrimination, and allocative efficiency in intermediate-goods markets, RAND Journal of Economics 40, 658-672.

Klumpp, T. and X. Su (2010). Open Access and Dynamic Efficiency, American Economic Journal: Microeconomics 2, 64-96.

Laffont, Jean-Jacques, and Jean Tirole (1993). A Theory of Incentives in Procurement and Regulation, Cambridge, MA: MIT Press.

Mitchell, B.M., and I. Vogelsang (1991). Telecommunications Pricing: Theory and Practice, Cambridge, UK: Cambridge University Press.

Ordover, J.A., and J.C. Panzar (1980). On the Nonexistence of Pareto Superior Outlay Schedules, Bell Journal of Economics 11, 351-354. 
Ordover, J.A., and J.C. Panzar (1982). On the Nonlinear Pricing of Inputs, International Economic Review 23, 659-675.

Panzar, J.C., and D.S. Sibley (1989). Optimal Two-part Tariffs for Inputs - The Case of Imperfect Competition, Journal of Public Economics 40, 237-249.

Valletti, T. (1998). Two-part access pricing and imperfect competition, Information Economics and Policy 10, 305-323.

Vogelsang, I. (2001). Price Regulation for Independent Transmission Companies, Journal of Regulatory Economics 20, 141-165.

Vogelsang, I. (2003). Price Regulation of Access to Telecommunications Networks, Journal of Economic Literature 41, 830-862.

Von Ungern-Sternberg, T. (1991). Monopolistic Competition in the Pyramid, Journal of Industrial Economics 39, 355-368.

Willig, R.D. (1978). Pareto-Superior Nonlinear Outlay Schedules, Bell Journal of Economics 9, 56-69. 